\title{
Examination of Dysglycaemia among Newly Diagnosed Tuberculosis Patients in Ghana: A Cross-Sectional Study
}

\author{
Ernest Yorke $\mathbb{D},{ }^{1}$ Vincent Boima, ${ }^{1}$ Ida Dzifa Dey, ${ }^{1}$ Yacoba Atiase $\left(\mathbb{D},{ }^{1}\right.$ Josephine Akpalu $\left(\mathbb{D},{ }^{1}\right.$ \\ Alfred Edwin Yawson $\mathbb{1}^{2},{ }^{2}$ Vincent Ganu, ${ }^{3}$ Audrey Forson, ${ }^{1}$ and C. Charles Mate-Kole ${ }^{4,5,6}$ \\ ${ }^{1}$ Department of Medicine \& Therapeutics, School of Medicine \& Dentistry, College of Health Sciences, University of Ghana, Ghana \\ ${ }^{2}$ Department of Community Health, School of Public Health, University of Ghana, Ghana \\ ${ }^{3}$ Department of Medicine, Korle-Bu Teaching Hospital, Accra, Ghana \\ ${ }^{4}$ Department of Psychiatry, School of Medicine \& Dentistry, College of Health Sciences, Korle-Bu, Ghana \\ ${ }^{5}$ Centre for Ageing Studies, College of Humanities, University of Ghana, Ghana \\ ${ }^{6}$ Department of Psychology, College of Humanities, University of Ghana, Ghana
}

Correspondence should be addressed to Ernest Yorke; pavlovium@yahoo.com

Received 29 May 2018; Accepted 5 September 2018; Published 24 September 2018

Academic Editor: Vincent Jarlier

Copyright (C) 2018 Ernest Yorke et al. This is an open access article distributed under the Creative Commons Attribution License, which permits unrestricted use, distribution, and reproduction in any medium, provided the original work is properly cited.

The burden of both tuberculosis (TB) and diabetes mellitus in developing countries including Ghana is high; often, the two coexist and impact each other negatively. Objective. The study aimed to determine the prevalence and predictive factors of dysglycaemia among newly diagnosed smear positive tuberculosis patients at a tertiary tuberculosis treatment centre in Ghana. Methods. Dysglycaemia at diagnosis was determined by the use of oral glucose tolerance test (OGTT), while sputum smear microscopy was used to assess the sputum status. Only smear positive patients were included in the study. Information on sociodemographic, anthropometrical, clinical, and medication history was also obtained. Results. In all, 146 participants, aged 18 to 75 years with a mean age of 38.7 years comprising 115 (78.8\%) males and 31 (21.2\%) females, were involved in the analysis. Upon initial screening, using fasting plasma glucose (FPG), 91.1\% had normal fasting level, $5.5 \%$ had impaired fasting, and 3.4\% were diagnosed with diabetes. Using 2-hour postprandial values (2HPP), $59.6 \%$ had normal plasma glucose, $28.8 \%$ had impaired glucose tolerance (IGT), and $11.6 \%$ were diagnosed with diabetes. Overall, the prevalence of dysglycaemia (i.e., impaired fasting and diabetes) was $8.9 \%$ (95\% CI: 5.21-14.82\%) with FPG test and 40.4\% (95\% CI: 32.68-48.65\%) with 2HPP test. The analysis revealed that 2HPP was associated with high mean age compared to FPG $(36.67 \pm 13.97$ versus $41.69 \pm 13.97$, p-value $=0.033)$. In addition, marital status was significantly associated with FPG status of patients $(\mathrm{p}=0.028)$. Conclusion. The prevalence of dysglycaemia was high among smear positive TB patients in Ghana. Higher mean age and marital status were associated with abnormal glucose tolerance and fasting plasma glucose, respectively. Clinical management of patients with tuberculosis should include screening for diabetes.

\section{Introduction}

Tuberculosis (TB) infections continue to be a concern worldwide and it remains a deadly communicable disease. The World Health Organisation (WHO) estimated that 10.4 million new cases of TB occurred and 1.4 million died from the disease in 2015 despite several preventive strategies to reduce the burden and impact [1]. Over $70 \%$ of these new cases occurred in developing countries with the African region experiencing the highest rate of death relative to the population [1].
Diabetes and TB as separate disease entities impact negatively on each other [2]. Although at the population level, HIV is the most important risk factor for TB [1], diabetes, which causes impaired immunity, has long been recognized as a risk factor for infections including TB [3]. Diabetes is a risk factor for lower respiratory infections including TB. A review by Steven et al. reported that diabetes increases TB risk by 1.5- to 7.8-fold [4]. Another meta-analysis by Joen et al. reported that the relative risk for TB among diabetes patients was 3.11 [5]. They stated that the prevalence of diabetes ranged from $1.9 \%$ to $35 \%$ after screening TB patients; the highest rates 
were among regions of the world with the highest diabetes prevalence [5]. Also, a study from United States of America reported that the odds ratio of multidrug resistant (MDR) TB associated with diabetes patients is 2.1 [6].

Diabetes may affect the presentation of TB by being associated with more cavitations [6], lower lobe involvements [2], higher rates of haemoptysis [6], fever [6], increased risk of treatment failure, relapse, and death[7]. Further, diabetes may affect the pharmacokinetics of rifampicin, a major component of anti-TB medications, and reduce its plasma concentration [8]. However, it is not clear whether the reduced plasma concentrations of rifampicin affect treatment outcomes $[2,8]$.

Studies have reported that TB could lead to impaired glucose tolerance (IGT) [9] and new onset diabetes [10, 11]. Generally, IGT normalises after the TB has been successfully treated, but it remains a significant risk factor for developing type 2 diabetes in the future [12].

This hyperglycaemia caused by TB infection may lead to overdiagnosis of diabetes in previously unscreened TB patients [3] and can also worsen glycaemic control in previously diagnosed diabetes patients [12]. The latter situation may, therefore, warrant adjustment in doses of antiglycemic agents or a complete switch to insulin therapy.

The present study examined the burden of dysglycaemia among newly diagnosed smear positive tuberculosis patients at a tertiary tuberculosis treatment centre and explored factors that might predict dysglycaemia among these patients.

\section{Materials and Methods}

2.1. Study Design and Site. The study was a hospital based cross-sectional study carried out at the Chest Clinic of the Korle-Bu Teaching Hospital, a tertiary care facility and the largest hospital in Ghana. The Korle-Bu Chest Clinic serves as the main referral centre for respiratory and $\mathrm{TB}$ cases for the southern part of the country.

2.2. Participants. Participants were newly diagnosed smear positive TB patients that were referred to the treatment centre of Korle-Bu Chest Clinic.

Patients aged 18 years and over with no previous history of TB treatment were recruited. All the participants gave informed consent. Exclusion criteria indicated participants with smear negative TB cases, those with extrapulmonary TB or those who refused consent.

2.3. Sampling. All smear positive TB patients who met the inclusion criteria were recruited on weekdays over a 12 month period. One hundred and ninety smear positive TB patients were sampled at the end of the study period, of which 44 did not stay to complete the full OGTT test or refused consent.

2.4. Measurements. At study enrolment, participants were administered a questionnaire to assess and document demographic and anthropometric characteristics as well as medical history
Calculated body mass index (BMI) was categorized as obesity, overweight, normal, and underweight and were defined as 30.0 or more, 25-29.9, 18.5-24.9, and less than 18.5 $\left(\mathrm{Kg} / \mathrm{m}^{2}\right)$, respectively [13].

A $75 \mathrm{~g}$ oral glucose tolerance test (OGTT) was used to determine impaired glucose tolerance (IGT), impaired fasting glucose (IFG), and diabetes at diagnosis. 10ml fasting blood sample was taken into fluoridated blood sample tubes (kept on ice and centrifuged within 15 minutes of blood draw), ethylene-diamine-tetra-acetic acid (EDTA) tubes, and plain tubes [14]. Patients then received $75 \mathrm{~g}$ glucose in $250 \mathrm{ml}$ water, and after 2 hours blood sample was taken into fluoridated sample tubes and processed similarly as the fasting sample. Plasma glucose was determined by glucose oxidase commercial reagent kits and controls (DiaSys, GmbH, Germany). Diagnoses of impaired fasting and glucose tolerance were made when FPG and 2HPP values are 6.1-6.9 mmol/l and 7.8-11 mmol/l, respectively. Diabetes was diagnosed when FPG and $2 \mathrm{HPP}$ are $>7 \mathrm{mmol} / \mathrm{l}$ and $>11.1 \mathrm{mmol} / \mathrm{l}$, respectively, or on regular medication for diabetes. FPG and $2 \mathrm{HPP}$ values below $6.1 \mathrm{mmol} / \mathrm{l}$ and $7.8 \mathrm{mmol} / \mathrm{l}$ are normal [15].

Microscopy for acid fact bacilli (AFBs) was performed using Ziehl-Neelsen (ZN) stain. Patients found to have diabetes were referred to receive appropriate care.

2.5. Ethical Considerations. All patients provided written informed consent. The study received approval from the University of Ghana College of Health Sciences Ethics and Protocol Review Committee prior to the commencement of the study with reference number URF/9/ILG-076/2015-2016.

We complied with the Helsinki Declaration of 1964 (Revised 2013) on human experimentation. Strict confidentiality of data and privacy for study participants were ensured. Data was kept secured and was available only to the principal investigator.

2.6. Statistical Analysis. Data was entered into Microsoft Excel 2010 version and imported into the Statistical software STATA version 15 for analysis. Analysis was done for 146 patients with complete data.

Descriptive statistics of the sociodemographic, anthropometric, clinical and glycaemic variables were summarised as frequencies, percentages, means, and standard deviations.

Chi-square and Fisher's exact tests were used to test for association between the plasma glucose status of participants (categorized as normal and abnormal plasma glucose level) and other categorical independent variables; while t-test was used for comparing means of continuous variables among smear positive TB patients with normal and abnormal plasma glucose levels.

Binary logistic regression models and Poisson regression model were used to test the effect of sociodemographic, clinical, and lifestyle factors on the outcome variables, $2 \mathrm{HPP}$ and FBG, respectively. Poisson model was chosen over logistic regression model because of the very low prevalence of abnormal FBG glucose level [16]. Potential for effect modification was examined by testing the significance of interactions. Only statistically significant interaction terms 
were retained in the final models. The statistical tests were set at $5 \%$ significance level.

\section{Results}

One hundred and forty-six (146) participants, aged 18 to 75 years with a mean age of 38.7 years comprising $115(78.8 \%)$ males and $31(21.2 \%)$ females, were involved in the analysis. Seven out of every ten selected smear positive TB patients were underweight. Mean values $( \pm$ SD) of some clinical parameters such as weight, height, waist circumference, hip circumference, systolic blood pressure, and diastolic blood pressure are $52.74 \pm 8.94 \mathrm{Kg}, 1.68 \pm 0.08 \mathrm{~m}, 76.25 \pm 7.32$ $\mathrm{cm}, 89.37 \pm 7.43 \mathrm{~cm}, 117.61 \pm 21.76 \mathrm{mmHg}$, and $77.13 \pm$ $12.10 \mathrm{mmHg}$, respectively. Detailed distribution of sociodemographic, anthropometric, and other clinical characteristics of the participants can be found in Table 1 .

3.1. Prevalence of Diabetes and Dysglycaemia. After screening, using fasting plasma glucose, $91.1 \%$ had normal fasting level, $5.5 \%$ had impaired fasting, and $3.4 \%$ were diagnosed to be diabetic. Using 2-hour postprandial values (2HPP), 59.6\% had normal plasma glucose, $28.8 \%$ had impaired glucose tolerance, and 17 out of 146 (11.6\%) had diabetes. In all, the combined prevalence of dysglycaemia using fasting values was $8.9 \%$ (95\% CI: 5.21-14.82\%) (i.e., impaired fasting and diabetes) while that for postprandial values (impaired glucose tolerance and diabetes) was 40.4\% (95\% CI: 32.68-48.65\%) (Table 1).

3.2. Association between Sociodemographic Factors, Clinical Factors, Lifestyle Factors and 2HPP Status. The bivariate analysis of factors associated with 2HPP status (Table 2) revealed that mean age was significantly associated with 2HPP status, where those with abnormal 2HPP had higher mean age $(36.67 \pm 13.97$ vs $41.69 \pm 13.97, \mathrm{p}-$ value $=$ 0.033).

3.3. Association between Sociodemographic Factors, Clinical Factors, Lifestyle Factors and FPG Status. The bivariate analysis of factors associated with FPG status (Table 3) revealed that marital status was associated with FPG status of patients; the proportion of patients with abnormal FPG was significantly higher among separated/divorced participants $(33.3 \%)$, while the married ones had the least $6.5 \%\left(\chi^{2}=\right.$ $7.16, \mathrm{p}=0.028)$. The other factors did not have any statistically significant association with FPG status ( $p>0.05)$. See Table 3.

3.4. Evaluating Effects of Sociodemographic Factors on $2 \mathrm{HPP}$ Status. The results from multiple binary logistic regression analysis showed that none of the sociodemographic factors was statistically significant in predicting the $2 \mathrm{HPP}$ status of patients. Refer to Table 4. The effects of sociodemographic factors on 2HPP status were assessed in six different nested models with only sociodemographic characteristics of the study participants. These models were assessed and evaluated with Area under Receiver Operating Characteristic Curve (AUROC) and Akaike Information Criterion (AIC).

Although, statistically, AUROC did not vary significantly across the six nested models $\left(\chi^{2}=5.07, \mathrm{p}=0.408\right)$, model 6 was the best performing model (AUROC $=69.9 \%$, AIC=208.6). Detailed evaluation of the six models and graph showing the performance of the models can be found under Supplementary Materials I \& II, respectively.

Analysis investigated the effect of clinical, lifestyle, and socioeconomic factors on $2 \mathrm{HPP}$ status. After controlling for sociodemographic factors, there is no enough statistical evidence to conclude that any of the clinical and lifestyle factors have significant effect on 2HPP status ( $p>0.05)$ (Table 5). The detailed assessment of the statistical models used based on Area under Receiver Operating Characteristic Curve (AUROC) and Akaike Information Criterion (AIC) is shown under Supplementary Materials III.

\subsection{Effects of Sociodemographic, Clinical, and Lifestyle Factors} on FPG Status. The results from the Poisson regression model showed that there is no enough statistical evidence to conclude that any of the sociodemographic factors, clinical conditions, and lifestyle factors have significant effect on FPG status of patients ( $p>0.05)$, Table 6 .

\section{Discussion}

We found a high prevalence of dysglycaemia in our study (i.e., $8.9 \%$ and $40.4 \%$ ) by fasting and postprandial values, respectively, as well as diabetes of $3.4 \%$ and $11.6 \%$ by fasting and 2-hour post-glucose values, respectively. These findings were similar to other studies where $5-30 \%$ of TB patients were found to have diabetes [17-19].

Diabetes is significant risk factor for $\mathrm{TB}$ at the population level [3] and increases TB risk by 1.5 to 7.8 times [4]. A study by Joen et al. found that the relative risk for TB among diabetes patients was 3.11 [5], while a review by Alisjahbana et al. [6] suggested that the odds ratio of multidrug resistant (MDR) TB associated with diabetes patients is 2.1. Joen et al. [5] in a subsequent study reported that after screening TB patients, diabetes prevalence ranged from $1.9 \%$ to as high as $35 \%$. They observed that rates were higher in regions of the world where diabetes prevalence was also higher.

Diabetes impact on TB as a disease entity and its management in many ways. Some studies have shown that diabetes patients tend to show more lower lobe involvement than their nondiabetic counterparts due to reactivation of old foci [2]. Alisjahbana et al. reported lower rates of cavitations in some studies while others have higher rates [6]. Comorbid $\mathrm{TB}$ and diabetes may also be associated with higher rates of haemoptysis, fever, and atypical presentations [6]. Baker et al. in a systematic review reported that patients with diabetes have a risk ratio (RR) for the combined outcome of failure and death of 1.69 (95\% CI, 1.36 to 2.12), while the RR of death during tuberculosis treatment among 23 unadjusted studies was 1.89 (95\% CI, 1.52 to 2.36) [7]. In this same review, diabetes was also associated with an increased risk of relapse (RR, 3.89; 95\% CI, 2.43 to 6.23 ) [7]. 
TABLE 1: Background characteristics of study participants.

\begin{tabular}{|c|c|c|}
\hline & Frequency & Percentage \\
\hline Age, years $($ mean $\pm S D)$ & $38.70 \pm 13.97$ & \\
\hline \multicolumn{3}{|l|}{ Sex } \\
\hline Male & 115 & 78.80 \\
\hline Female & 31 & 21.20 \\
\hline \multicolumn{3}{|l|}{ Marital Status } \\
\hline Married & 62 & 42.47 \\
\hline Single & 75 & 51.37 \\
\hline Separated/Divorced & 9 & 6.16 \\
\hline \multicolumn{3}{|l|}{ Highest educational level } \\
\hline None & 13 & 8.90 \\
\hline Primary & 14 & 9.59 \\
\hline Middle School/ JHS & 54 & 36.99 \\
\hline O-Level/A-level/SHS & 32 & 21.92 \\
\hline Tertiary & 23 & 15.75 \\
\hline Other & 10 & 6.85 \\
\hline \multicolumn{3}{|l|}{ Employment status } \\
\hline Unemployed & 38 & 26.03 \\
\hline Employed & 108 & 73.97 \\
\hline \multicolumn{3}{|l|}{ Lifestyle factors } \\
\hline \multicolumn{3}{|l|}{ Smoking } \\
\hline Yes & 10 & 6.85 \\
\hline No & 136 & 93.15 \\
\hline \multicolumn{3}{|l|}{ Alcohol intake } \\
\hline Yes & 22 & 15.07 \\
\hline No & 124 & 84.93 \\
\hline \multicolumn{3}{|l|}{ Clinical factors } \\
\hline \multicolumn{3}{|l|}{ BMI $\left(\mathrm{Kg} / \mathrm{m}^{2}\right)$} \\
\hline Mean \pm SD & $18.49 \pm 3.00$ & \\
\hline Below 18.5 (Underweight) & 103 & 70.55 \\
\hline 18.5-24.9 (Normal) & 40 & 27.4 \\
\hline 25-29.9 (Over Weight) & 2 & 1.37 \\
\hline Above 30 (Obese) & 1 & 0.68 \\
\hline \multicolumn{3}{|l|}{ Glycaemic Variables } \\
\hline \multicolumn{3}{|c|}{ Fasting Plasma Glucose $(\mathrm{mmol} / \mathrm{L})$} \\
\hline$($ mean $\pm S D)$ & $5.12 \pm 1.52$ & \\
\hline Normal $(<6.1)$ & 133 & 91.1 \\
\hline Impaired (6.1-7) & 8 & 5.48 \\
\hline Diabetes $(>7.1)$ & 5 & 3.42 \\
\hline \multicolumn{3}{|l|}{2 HPP Glucose (mmol/L) } \\
\hline$($ mean $\pm S D)$ & $8.35 \pm 3.44$ & \\
\hline Normal $(<6.1)$ & 87 & 59.59 \\
\hline Impaired (6.1-7) & 42 & 28.77 \\
\hline Diabetes $(>7.1)$ & 17 & 11.64 \\
\hline
\end{tabular}

Diabetes can affect the pharmacokinetics of anti-TB drugs especially rifampicin and reduce their plasma concentrations [8]. There are however conflicting reports regarding whether the efficacy of TB treatment is affected by this interaction $[2,8]$. Consequently, the regimen for treatment of TB among both diabetics and nondiabetics is the same $[3,8]$. Also, the general approach to management of diabetes does not differ in the presence of TB or not. The treatment of diabetes with concomitant TB infection requires careful evaluation and choice of antiglycemic medication [1, 3]. In many situations, insulin is the preferred agent in type 2 diabetes where there is active TB infection [3]. Appropriate diet 
TABLE 2: Association between sociodemographic factors, clinical factors, and lifestyle factors and 2HPP Status.

\begin{tabular}{|c|c|c|c|c|}
\hline \multicolumn{5}{|c|}{$2 \mathrm{HPP}$} \\
\hline & Normal & Abnormal & $\chi^{2}$ & p-value \\
\hline Age $($ Mean \pm SD $)$ & $36.67 \pm 13.97$ & $41.69 \pm 13.97$ & -2.15 (t-test) & $0.033 *$ \\
\hline Sex & & & 1.09 & 0.297 \\
\hline Male & $66(57.39)$ & $49(42.61)$ & & \\
\hline Female & $21(67.74)$ & $10(32.26)$ & & \\
\hline Marital Status & & & 1.21 & 0.546 \\
\hline Married & $36(58.06)$ & $26(41.94)$ & & \\
\hline Single & $47(62.67)$ & $28(37.33)$ & & \\
\hline Separated/Divorced & $4(44.44)$ & $5(55.6)$ & & \\
\hline Highest Educational Level & & & 9.65 & 0.086 \\
\hline None & $9(69.23)$ & $4(30.77)$ & & \\
\hline Primary & $8(57.14)$ & $6(42.86)$ & & \\
\hline Middle School/ JHS & $24(44.44)$ & $30(55.56)$ & & \\
\hline SHS/ O-level & $23(71.88)$ & $9(28.13)$ & & \\
\hline Tertiary & $17(73.91)$ & $6(26.09)$ & & \\
\hline Other & $6(60.00)$ & $4(40.00)$ & & \\
\hline Employment Status & & & 0.82 & 0.365 \\
\hline Unemployed & $25(65.79)$ & $13(34.21)$ & & \\
\hline Employed & $62(57.41)$ & $46(42.59)$ & & \\
\hline \multicolumn{5}{|l|}{ Lifestyle Factors } \\
\hline Smoking & & & & $0.74 \S$ \\
\hline Yes & $7(70.00)$ & $3(30.00)$ & & \\
\hline No & $80(58.82)$ & $56(41.18)$ & & \\
\hline Alcohol Intake & & & 0.18 & 0.675 \\
\hline Yes & $14(63.64)$ & $8(36.36)$ & & \\
\hline No & $73(58.87)$ & $51(41.13)$ & & \\
\hline \multicolumn{5}{|l|}{ Clinical Factors } \\
\hline Weight (Mean \pm SD), Kg & $53.72 \pm 8.53$ & $51.31 \pm 9.41$ & 1.58 & 0.117 \\
\hline Height (Mean \pm SD), $\mathrm{m}$ & $1.67 \pm 0.08$ & $1.68 \pm 0.08$ & 0.85 & 0.40 \\
\hline \multicolumn{5}{|l|}{$\mathrm{BMI}\left(\mathrm{Kg} / \mathrm{m}^{2}\right)$} \\
\hline Mean \pm SD & $18.80 \pm 2.73$ & $18.02 \pm 3.33$ & 1.51 & 0.135 \\
\hline Below 18.5 (Underweight) & $59(57.28)$ & $44(42.72)$ & & 0.369 \\
\hline 18.5-24.9 (Normal) & $26(65.00)$ & $14(35.00)$ & & \\
\hline 25-29.9 (Over Weight) & $2(100.00)$ & 0 & & \\
\hline Above 30 Obese) & 0 & $1(100.00)$ & & \\
\hline Waist and Hip Circumference, $\mathrm{cm}$ & $76.00 \pm 7.10$ & $76.62 \pm 7.68$ & -0.5 & 0.619 \\
\hline \multicolumn{5}{|l|}{ Waist Circumference (Mean \pm SD) } \\
\hline Hip Circumference $($ Mean \pm SD) & $89.53 \pm 7.65$ & $89.14 \pm 7.13$ & 0.31 & 0.756 \\
\hline Waist-Hip Ratio (Mean \pm SD) & $0.86 \pm 0.06$ & $0.86 \pm 0.08$ & -0.22 & 0.824 \\
\hline Blood Pressure (mmHg) & $116.39 \pm 17.43$ & $119.42 \pm 26.99$ & -0.76 & 0.449 \\
\hline \multicolumn{5}{|l|}{ SBP $($ Mean \pm SD $)$} \\
\hline DBP $($ Mean \pm SD $)$ & $76.76 \pm 11.99$ & $77.66 \pm 12.35$ & -0.44 & 0.664 \\
\hline Pulse (Mean \pm SD) & $103.10 \pm 15.81$ & $107.10 \pm 18.40$ & -1.36 & 0.176 \\
\hline
\end{tabular}

$* \mathrm{p}<0.05$; values were based on Pearson chi-square and Fisher's exact test for categorical variables, and t-test for comparing the means. SD: standard deviation of age. (\%) represents row percentage and $₫$ p-value estimate from Fisher's exact test.

advice is also needed, aimed at balancing glycaemic control and the nutritional demands of largely underweight and malnourished TB patients [20].

Patients with abnormal 2HPP were more likely to have higher mean age values in this study. This may be a reflection of an underlying increased risk of type 2 diabetes which is prevalent among older people [21]. The incidence of diabetes increases with age until about the age of 65 years, after which both incidence and prevalence tend to plateau [21]. This group of patients tend to have multiple comorbidities 
TABLE 3: Association between sociodemographic factors, clinical factors, and lifestyle factors and FPG Status.

\begin{tabular}{|c|c|c|c|c|}
\hline \multicolumn{5}{|c|}{ FBG } \\
\hline & Normal & Abnormal & $x^{2}$ & p-value \\
\hline Age $($ Mean \pm SD) & $38.29 \pm 13.84$ & $42.85 \pm 15.21$ & -1.04 (t-test) & $0.316 \neq$ \\
\hline Sex & & & & $1.00 \$$ \\
\hline Male & 105(91.30) & $10(8.70)$ & & \\
\hline Female & $28(90.32)$ & $3(9.68)$ & & \\
\hline Marital Status & & & 7.16 & $0.028 *$ \\
\hline Married & $58(93.55)$ & $4(6.45)$ & & \\
\hline Single & $69(92.00)$ & $6(8.00)$ & & \\
\hline Separated/Divorced & $6(66.67)$ & $3(33.33)$ & & \\
\hline Highest Educational Level & & & & $0.433 \S$ \\
\hline None & $12(92.31)$ & $1(7.69)$ & & \\
\hline Primary & $13(92.86)$ & $1(7.14)$ & & \\
\hline Middle School/ JHS & $47(87.04)$ & $7(12.96)$ & & \\
\hline O-level/SHS & $31(96.88)$ & $1(3.13)$ & & \\
\hline Tertiary & $22(95.65)$ & $1(4.35)$ & & \\
\hline Other & $8(80.00)$ & $2(20.00)$ & & \\
\hline Employment Status & & & & $0.185 \S$ \\
\hline Unemployed & $37(97.37)$ & $1(2.63)$ & & \\
\hline Employed & $96(88.89)$ & 12(11.11) & & \\
\hline Smoking & & & & $1.00 \$$ \\
\hline Yes & $9(90.00)$ & $1(10.00)$ & & \\
\hline No & $124(91.18)$ & $12(8.82)$ & & \\
\hline Alcohol Intake & & & & $0.692 \S$ \\
\hline Yes & $21(95.45)$ & $1(4.55)$ & & \\
\hline No & $112(90.32)$ & $12(9.68)$ & & \\
\hline Clinical Factors & $53.05 \pm 9.02$ & $49.62 \pm 7.75$ & 1.5 & $0.153 \neq$ \\
\hline \multicolumn{5}{|l|}{ Weight (Mean \pm SD) } \\
\hline Height (Mean \pm SD) & $1.69 \pm 0.08$ & $1.66 \pm 0.06$ & 1.44 & $0.168 \neq$ \\
\hline \multicolumn{5}{|l|}{ BMI } \\
\hline Mean \pm SD & $18.52 \pm 3.02$ & $18.12 \pm 2.92$ & 0.47 & $0.647 \neq$ \\
\hline Below 18.5 (Underweight) & $94(91.26)$ & $9(8.74)$ & & $0.816 \S$ \\
\hline 18.5-24.9 (Normal) & $36(90.00)$ & $4(10.00)$ & & \\
\hline 25-29.9 (Over Weight) & $2(100.0)$ & 0 & & \\
\hline Above 30 (Obese) & $1(100.0)$ & 0 & & \\
\hline \multicolumn{5}{|l|}{ Waist Circumference } \\
\hline Waist Circumference (Mean \pm SD) & $76.30 \pm 7.48$ & $76.21 \pm 5.72$ & 0.05 & $0.963 \neq$ \\
\hline Hip Circumference (Mean \pm SD) & $89.55 \pm 7.48$ & $88.06 \pm 6.87$ & 0.74 & $0.472 \neq$ \\
\hline Waist-Hip Ratio (Mean \pm SD) & $0.85 \pm 0.07$ & $0.86 \pm 0.07$ & -0.3 & $0.769 \neq$ \\
\hline \multicolumn{5}{|l|}{ Blood Pressure } \\
\hline SBP $($ Mean \pm SD $)$ & $117.36 \pm 21.17$ & $120.23 \pm 28.05$ & -0.36 & $0.725 \neq$ \\
\hline DBP (Mean \pm SD) & $76.80 \pm 12.08$ & $80.5 \pm 12.35$ & -1.04 & $0.318 \neq$ \\
\hline Pulse (Mean \pm SD) & $104.15 \pm 17.17$ & $110.54 \pm 13.93$ & -1.54 & $0.142 \neq$ \\
\hline
\end{tabular}

$* \mathrm{p}<0.05$; values were based on Pearson chi-square and Fisher's exact test for categorical variables, and t-test for comparing the means. SD: standard deviation of age. (\%) represents row percentage, $\neq$ estimated p-value from the Welch t-test, and $₫$ p-value estimate from Fisher's exact test.

including diabetic microvascular and macrovascular complications, coupled with reduced functional status, and increased risk of institutionalization $[21,22]$. They also tend to be the productive work force and major family income earners. Additionally, older adults are more likely to develop extra-pulmonary and atypical disease patterns that are often harder to diagnose than conventional sputum smear positive pulmonary tuberculosis [23]. Consequently such patients with TB and diabetes are more likely to suffer worse morbidity, mortality, and social impact $[1,21,23]$.

Marital status was significantly associated with FPG status of patients; the proportion of patients with abnormal FPG 
TABLE 4: Effects of sociodemographic factors on 2HPP status (model six).

\begin{tabular}{lccc}
\hline & OR & 95\% IC & 0.118 \\
\hline Current age & 1.03 & $0.99-1.06$ \\
Highest educational level & & \\
None & Ref & \\
Primary & 1.58 & $0.3-8.36$ \\
Middle School/ JHS & 2.32 & $0.56-9.62$ \\
O-Level/SHS & 0.75 & $0.16-3.59$ \\
Tertiary & 0.71 & $0.14-3.64$ \\
Other & 1.04 & $0.15-7.12$ \\
Employment status & & \\
Unemployed & Ref & \\
Employed & 1.60 & $0.66-3.92$ \\
Sex & & \\
Male & Ref & \\
Female & 0.69 & $0.27-1.73$ \\
Marital status & & \\
Married & Ref & \\
Single & 1.32 & $0.54-3.22$ \\
Separated/Divorced & 1.37 & $0.3-6.29$ \\
\hline
\end{tabular}

TABLE 5: Evaluating the effect of clinical and lifestyle factors on 2HPP.

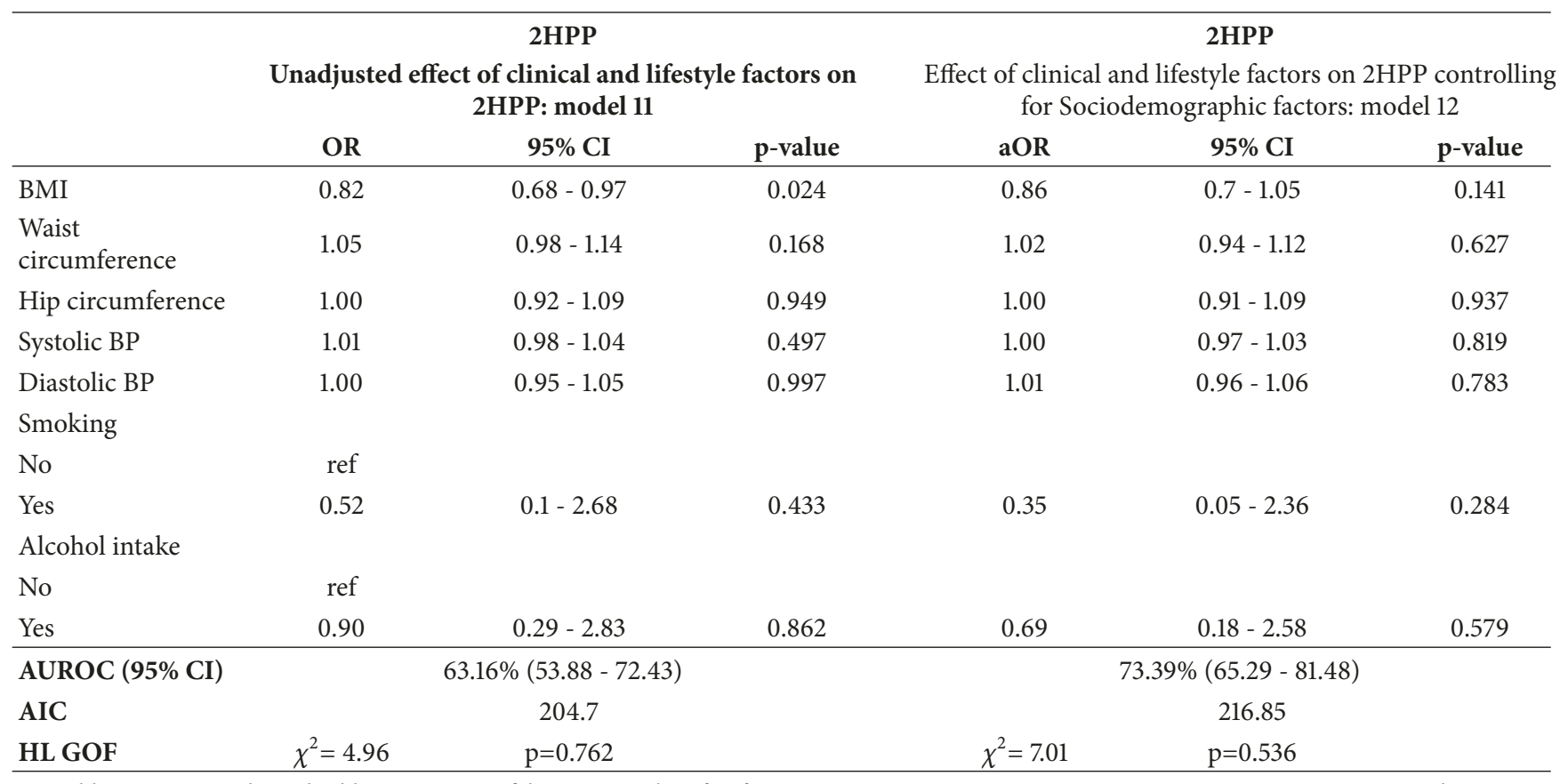

OR: odds ratio, aOR: adjusted odds ratio, CI: confidence interval, Ref: reference category, $* \mathrm{p}<0.05, * * \mathrm{p}<0.01, * * * \mathrm{p}<0.001$, AUROC: Area under receiver operating characteristic curve, AIC: Akaike Information Criterion, HL GOF: Hosmer Lemeshow Goodness of fit test.

turns to be high among patients who are separated/divorced (33.3\%), while the married ones had the least (6.5\%). It may be possible that stress among smear positive TB patients who are separated/divorced predisposes them to a higher risk of dysglycaemia. It is noteworthy that the numbers in the separated/divorced group were small and may not reflect the true situation.
The findings of most participants in this study, being male, young age, and single, are well known characteristics of TB patients $[1,24,25]$. Other risk factors include low-income earners, bacillary load, proximity to a person with active TB, malnutrition, alcohol abuse, smoking, overcrowding, HIV infection, diabetes, and immunosuppressive drug [1, $24,25]$. The participants also had low average BMI of 18.49 
TABLE 6: Effects of sociodemographics factors, clinical conditions, and lifestyle factors on FPG status.

\begin{tabular}{|c|c|c|c|c|c|c|}
\hline & \multicolumn{3}{|c|}{ Unadjusted } & \multicolumn{3}{|c|}{ Adjusted } \\
\hline & PR & 95\% CI & p-value & PR & 95\% CI & p-value \\
\hline Current age & 1.02 & $0.98-1.06$ & 0.287 & 1.00 & $0.94-1.06$ & 0.958 \\
\hline Highest educational level & & - & 0.603 & & - & 0.494 \\
\hline None & Ref & & & & & \\
\hline Primary & 0.93 & $0.06-14.85$ & & 0.67 & $0.03-14.83$ & \\
\hline Middle school/JHS & 1.69 & $0.21-13.7$ & & 2.40 & $0.23-25.2$ & \\
\hline SSS/O-level/SHS & 0.41 & $0.03-6.49$ & & 0.33 & $0.02-7.02$ & \\
\hline Tertiary & 0.57 & $0.04-9.04$ & & 0.66 & $0.04-12.03$ & \\
\hline Other & 2.60 & $0.24-28.67$ & & 3.00 & $0.18-50.36$ & \\
\hline Employment status & & - & 0.166 & & - & \\
\hline Unemployed & Ref & & & & & \\
\hline Employed & 4.22 & $0.55-32.47$ & & 7.73 & $0.87-68.57$ & 0.066 \\
\hline Sex & & - & 0.871 & & - & \\
\hline Male & Ref & & & & & \\
\hline Female & 1.11 & $0.31-4.04$ & & 0.95 & $0.2-4.6$ & 0.953 \\
\hline Marital status & & - & 0.067 & & - & 0.165 \\
\hline Married & Ref & & & & & \\
\hline Single & 1.24 & $0.35-4.39$ & & 1.12 & $0.21-5.92$ & \\
\hline Separated/Divorced & 5.17 & $1.16-23.08$ & & 6.12 & $0.9-41.56$ & \\
\hline BMI & 0.96 & $0.79-1.16$ & 0.661 & 0.96 & $0.68-1.35$ & 0.803 \\
\hline Waist Circumference & 1.00 & $0.93-1.08$ & 0.999 & 1.05 & $0.92-1.2$ & 0.460 \\
\hline Hip Circumference & 0.98 & $0.91-1.05$ & 0.534 & 0.95 & $0.82-1.1$ & 0.522 \\
\hline Systolic BP & 1.00 & $0.98-1.03$ & 0.663 & 0.96 & $0.91-1.02$ & 0.217 \\
\hline Diastolic BP & 1.02 & $0.98-1.06$ & 0.314 & 1.06 & $0.96-1.16$ & 0.245 \\
\hline Smoking & & - & 0.904 & & - & 0.427 \\
\hline No & Ref & & & & & \\
\hline Yes & 0.88 & $0.11-6.79$ & & 3.94 & $0.13-115.79$ & \\
\hline Alcohol intake & & - & 0.468 & & - & 0.289 \\
\hline \multicolumn{7}{|l|}{ No } \\
\hline Yes & 2.13 & $0.28-16.37$ & & 0.17 & $0.01-4.44$ & \\
\hline
\end{tabular}

Ref: the reference category, PR: prevalence ratio from the multiple Poisson regression model, CI: confidence interval. $\mathrm{p}<0.05, * * \mathrm{p}<0.01, * * * \mathrm{p}<0.001$.

$\pm 3.00 \mathrm{Kg} / \mathrm{m}^{2}$ with about $70 \%$ being underweight. TB patients tend to come from low socioeconomic background and generally malnourished and underweight [26]. The inflammatory response to infection $[27,28]$ as well as nausea, loss of appetite, and vomiting associated with TB is possible contributor to weight loss. Theoretically, diabetes may compound weight loss. Diabetes is associated with reduced insulin secretion or action, which results in an increased catabolic state with breakdown of body tissue and loss of calories leading to weight loss. However, in our study, there were no statistical differences in the mean BMI among those with normal and abnormal glucose values (both FBS and 2HPP).

\section{Conclusion}

The study found a high prevalence of dysglycaemia among smear positive TB patients similar to many previous studies on the subject. Higher mean age and marital status were associated with abnormal glucose tolerance and fasting plasma glucose, respectively. It is one of the very few studies done on this subject in the African subregion.

The findings of the study come to support the increasing recognition of the association between $\mathrm{TB}$ and diabetes. With a high burden of $\mathrm{TB}$ and increasing prevalence of diabetes in Africa, the findings also reinforce the call for the institutionalization of screening for diabetes among newly diagnosed TB patients in this part of the world.

\section{Limitations}

This study only described dysglycaemia at diagnosis and associated factors. Follow-up studies are needed to ascertain treatment outcomes among TB patients with dysglycaemia and those without.

\section{Abbreviations}

AFB: Acid fact bacilli

AIC: Akaike Information Criterion 
aOR: $\quad$ Adjusted odds ratio

AUROC: Area under Receiver Operating Characteristic Curve (AUROC)

BP: $\quad$ Blood pressure

BMI: $\quad$ Body mass index

CI: $\quad$ Confidence Interval

EDTA: Ethylene-diamine-tetra-acetic acid

FPG: $\quad$ Fasting plasma glucose

HIV: Human Immunodeficiency virus

HL GOF: Hosmer Lemeshow Goodness of fit test

IGT: Impaired glucose tolerance

MDR: Multidrug resistant tuberculosis

OGTT: Oral glucose tolerance test

OR: $\quad$ Odds ratio

SD: $\quad$ Standard deviation

TB: Tuberculosis

WHO: World Health Organisation

ZN: Ziehl-Neelsen

2HPP: 2-hour postprandial glucose.

\section{Data Availability}

The data used to support the findings of this study are available from the corresponding author upon request.

\section{Conflicts of Interest}

There are no conflicts of interest involving any of the authors of this manuscript.

\section{Authors' Contributions}

Ernest Yorke conceived the study; participated in its design, data collection, and analysis; drafted the manuscript; and collated all drafts. Vincent Boima, Yacoba Atiase, Alfred Edwin Yawson, Vincent Ganu, Audrey Forson, and C. Charles MateKole contributed to study design, data collection, analysis, and manuscript draft. All authors read and approved the final version of the manuscript.

\section{Acknowledgments}

This study was mostly funded by a University of Ghana Office of Research, Innovation and Development (ORID) grant (Project Reference Number: URF/9/ILG-076/2015-2016). We also appreciate the contribution of Nora Nkornu, Mavis Esenam Oman, Kelvin Acquaye, and Ernest Amaning-Kwarteng especially with respect to data collection.

\section{Supplementary Materials}

I, II: comparison of the performance of six nested models used in assessing the effect of sociodemographic factors on 2HPP (2-hour postprandial glucose) status. III: comparison of the performance of two nested models used in assessing the effect of clinical and lifestyle factors on 2HPP (2-hour postprandial glucose) status. (Supplementary Materials)

\section{References}

[1] World Health O: Global tuberculosis report 2016. 2016.

[2] R. M. Wilson, "Infection and diabetes mellitus," in Textbook of diabetes, J. C. Pickup and G. Williams, Eds., pp. 813-819, Blackwell Scientific Publication, Oxford, 1991.

[3] A. K. Niazi and S. Kalra, "Diabetes and tuberculosis: a review of the role of optimal glycemic control," Journal of Diabetes and Metabolic Disorders, vol. 11, no. 1, article 28, 2012.

[4] C. R. Stevenson, J. A. Critchley, N. G. Forouhi et al., "Diabetes and the risk of tuberculosis: A neglected threat to public health?" Chronic Illness, vol. 3, no. 3, pp. 228-245, 2007.

[5] C. Y. Jeon and M. B. Murray, "Diabetes Mellitus Increases the Risk of Active Tuberculosis: A Systematic Review of 13 Observational Studies," PLoS Medicine, vol. 5, no. 7, Article ID 0050152, 2008.

[6] B. Alisjahbana, E. Sahiratmadja, E. J. Nelwan et al., "The effect of type 2 diabetes mellitus on the presentation and treatment response of pulmonary tuberculosis," Clinical Infectious Diseases, vol. 45, no. 4, pp. 428-435, 2007.

[7] M. A. Baker, A. D. Harries, C. Y. Jeon et al., "The impact of diabetes on tuberculosis treatment outcomes: a systematic review," BMC Medicine, vol. 9, article 81, 2011.

[8] P. Baghaei, M. Marjani, P. Javanmard, P. Tabarsi, and M. R. Masjedi, "Diabetes mellitus and tuberculosis facts and controversies," Journal of Diabetes and Metabolic Disorders, vol. 12, no. 1, article 58, 2013.

[9] C. Y. Jeon, A. D. Harries, M. A. Baker et al., "Bi-directional screening for tuberculosis and diabetes: A systematic review," Tropical Medicine \& International Health, vol. 15, no. 11, pp. 1300-1314, 2010.

[10] F. Mugusi, A. B. M. Swai, K. G. M. M. Alberti, and D. G. McLarty, "Increased prevalence of diabetes mellitus in patients with pulmonary tuberculosis in Tanzania," Tuberculosis, vol. 71, no. 4, pp. 271-276, 1990.

[11] GP. Nichols, "Diabetes among young tuberculous patients; a review of the association of the two diseases," Am Rev Tuberc, vol. 76, no. 6, pp. 1016-1030, 1957.

[12] A. Guptan and A. Shah, "Tuberculosis and diabetes: an appraisal," Ind J Tub, vol. 47, no. 3, pp. 2-8, 2000.

[13] K. G. M. M. Alberti, P. Zimmet, and J. Shaw, "Metabolic syndrome-a new world-wide definition. A consensus statement from the International Diabetes Federation," Diabetic Medicine, vol. 23, no. 5, pp. 469-480, 2006.

[14] D. B. Sacks, D. E. Bruns, D. E. Goldstein et al., "Guidelines and recommendations for laboratory analysis in the diagnosis and management of diabetes mellitus," Clin Chem, vol. 48, no. 3, pp. 436-472, 2002.

[15] Organization WH: International Diabetes Federation (2006) Definition and diagnosis of diabetes mellitus and intermediate hyperglycemia: report of a WHO/IDF consultation. IDF consultation 2008

[16] L. M. S. Coutinho, M. Scazufca, and P. R. Menezes, "Methods for estimating prevalence ratios in cross-sectional studies," Revista de Saúde Pública, vol. 42, no. 6, pp. 992-998, 2008.

[17] A. Ponce-De-Leon, M. D. L. Garcia-Garcia, M. C. GarciaSancho et al., "Tuberculosis and diabetes in Southern Mexico," Diabetes Care, vol. 27, no. 7, pp. 1584-1590, 2004.

[18] A. Pablos-Méndez, J. Blustein, and C. A. Knirsch, "The role of diabetes mellitus in the higher prevalence of tuberculosis among Hispanics," American Journal of Public Health, vol. 87, no. 4, pp. 574-579, 1997. 
[19] R. Singla, N. Khan, N. Al-Sharif, M. O. Al-Sayegh, M. A. Shaikh, and M. M. Osman, "Influence of diabetes on manifestations and treatment outcome of pulmonary TB patients," The International Journal of Tuberculosis and Lung Disease, vol. 10, no. 1, pp. 74-79, 2006.

[20] Standards of Medical Care in Diabetes-2017. Diabetes Care 2017; 40 (Suppl. 1):S1-S2.

[21] M. S. Kirkman, V. J. Briscoe, N. Clark et al., "Diabetes in older adults," Diabetes Care, vol. 35, no. 12, pp. 2650-2664, 2012.

[22] California Healthcare Foundation, "Guidelines for Improving the Care of the Older Person with Diabetes Mellitus," Journal of the American Geriatrics Society, vol. 51, no. 5s, pp. 265-280, 2003.

[23] J. Negin, S. Abimbola, and B. J. Marais, “Tuberculosis among older adults - time to take notice," International Journal of Infectious Diseases, vol. 32, pp. 135-137, 2015.

[24] H. Amare, A. Gelaw, B. Anagaw, and B. Gelaw, "Smear positive pulmonary tuberculosis among diabetic patients at the Dessie referral hospital, Northeast Ethiopia," Infectious Diseases of Poverty, vol. 2, no. 1, 2013.

[25] P. Narasimhan, J. Wood, C. R. Macintyre, and D. Mathai, "Risk factors for tuberculosis," Pulmonary Medicine, vol. 2013, Article ID 828939, 11 pages, 2013.

[26] O. Oxlade and M. Murray, "Tuberculosis and Poverty: Why Are the Poor at Greater Risk in India?" PLoS ONE, vol. 7, no. 11, 2012.

[27] P. Matthys and A. Billiau, "Cytokines and cachexia," Nutrition Journal, vol. 13, no. 9, pp. 763-770, 1997.

[28] R. Van Crevel, E. Karyadi, M. G. Netea et al., "Decreased plasma leptin concentrations in tuberculosis patients are associated with wasting and inflammation," The Journal of Clinical Endocrinology \& Metabolism, vol. 87, no. 2, pp. 758-763, 2002. 


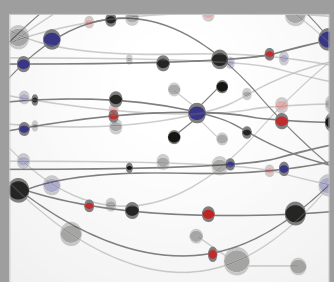

The Scientific World Journal
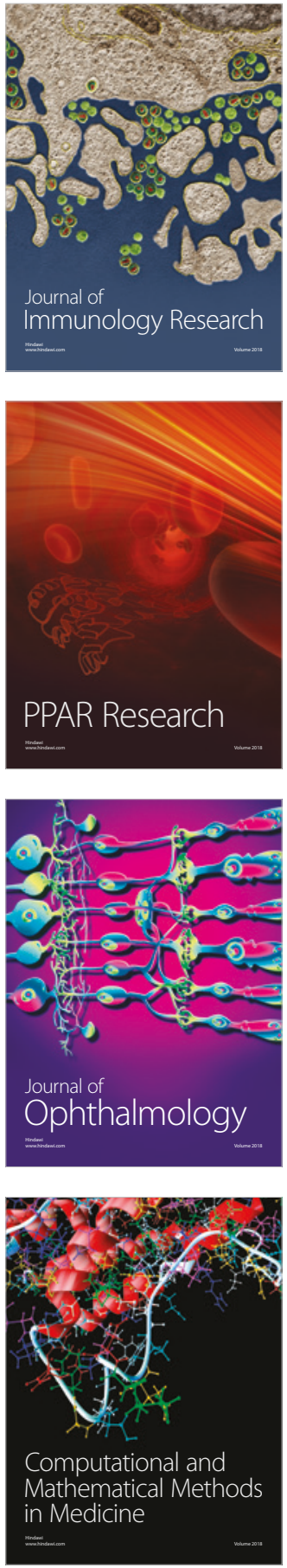

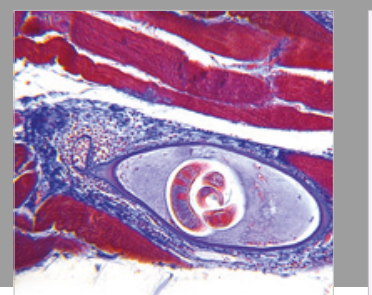

Gastroenterology Research and Practice

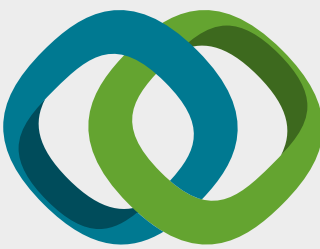

\section{Hindawi}

Submit your manuscripts at

www.hindawi.com
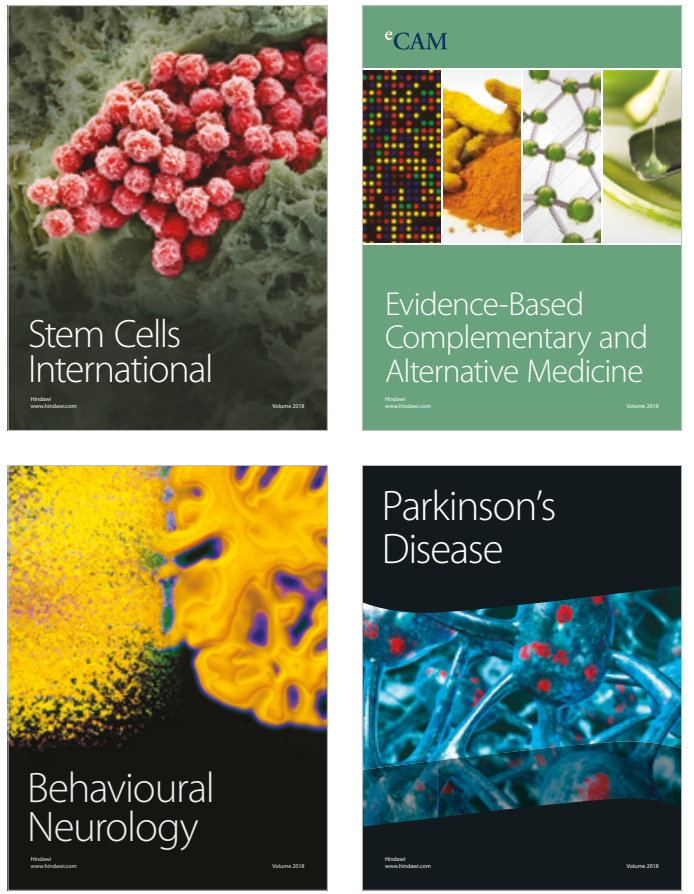

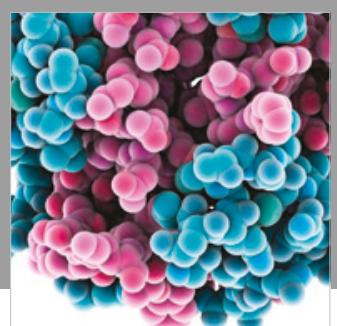

ournal of

Diabetes Research

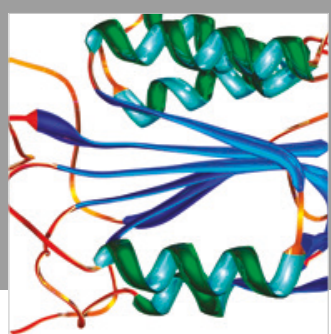

Disease Markers
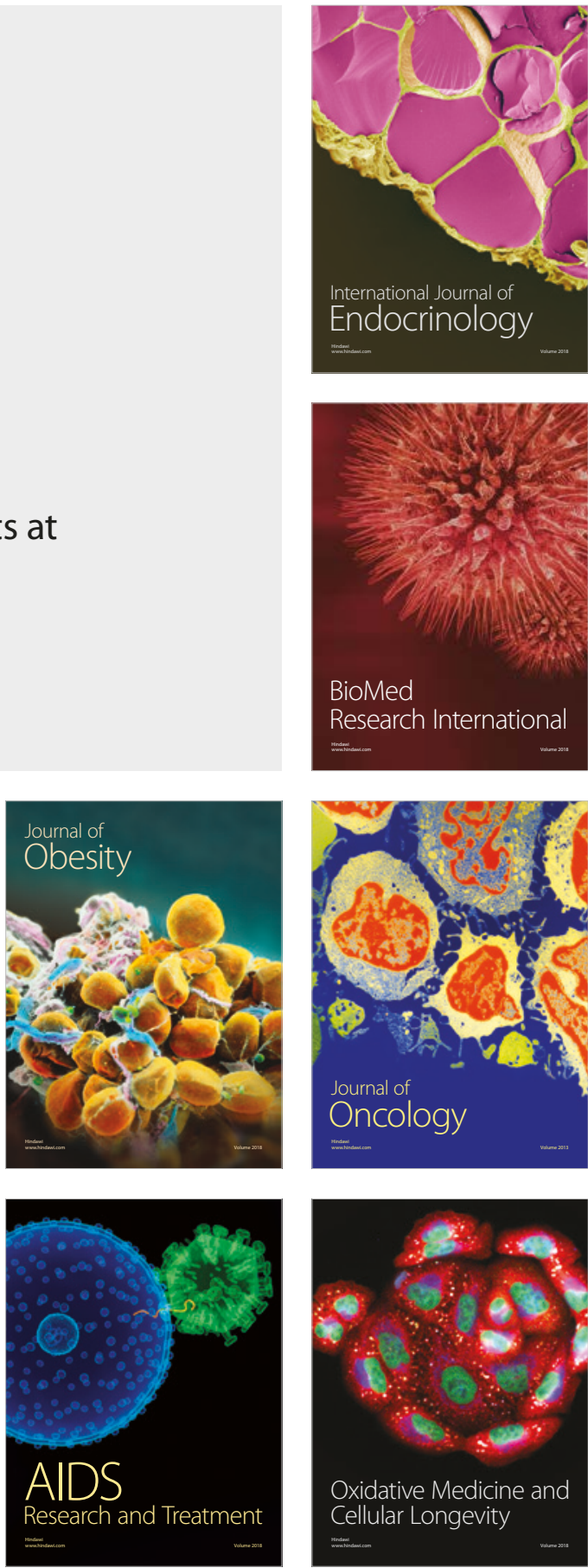